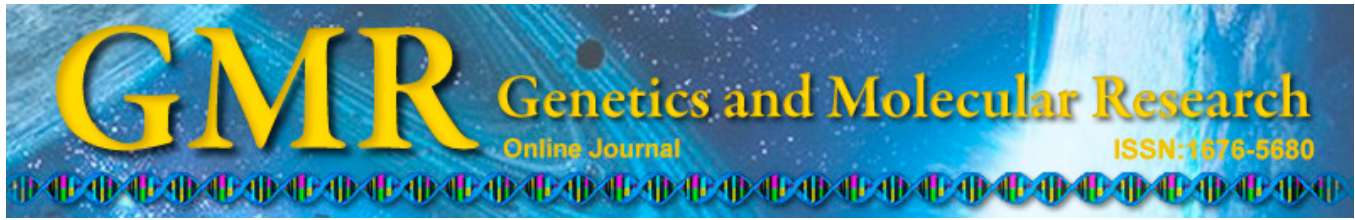

\title{
Monitoring tissue blood oxygen saturation in the internal jugular venous area using near infrared spectroscopy
}

\author{
Z.S. Ruan ${ }^{1 *}$, T. Li $^{2 *}$, R.R. Ren ${ }^{1 *}$, Y. Zhao ${ }^{2}$, K. Li $^{2}$, Y.F. Mao ${ }^{1}$, G. Shen ${ }^{1}$ \\ and L. Jiang ${ }^{1}$ \\ ${ }^{1}$ Department of Anesthesiology and Surgical Intensive Care Unit, \\ Xin Hua Hospital, Shanghai Jiao Tong University School of Medicine, \\ Shanghai, China \\ ${ }^{2}$ State Key laboratory of Electronic Thin Films and Integrated Devices and \\ Biomedical Engineering Department, \\ University of Electronic Science \& Technology, Chengdu, China \\ *These authors contributed equally to this study. \\ Corresponding author: L. Jiang \\ E-mail: laij_laij@163.com
}

Genet. Mol. Res. 14 (1): 2920-2928 (2015)

Received June 24, 2014

Accepted October 27, 2014

Published March 31, 2015

DOI http://dx.doi.org/10.4238/2015.March.31.23

\begin{abstract}
Central venous blood oxygen saturation $\left(\mathrm{ScvO}_{2}\right)$ is an important monitoring index of fluid resuscitation. However, monitoring of $\mathrm{ScvO}_{2}$ is not continuous and invasive. Near infrared spectroscopy (NIRS) is an optical technology for the noninvasive detection of hemodynamic changes, with advantages of being real-time, continuous, low-cost, and portable. The present study aimed to determine whether a correlation exists between the tissue blood oxygen saturation in the internal jugular venous area $\left(\mathrm{StO}_{2}\right)$ data obtained with NIRS and the $\mathrm{ScvO}_{2}$ and whether these two quantities are equivalent. Data were collected from 13 patients. We used ultrasound to locate the placement site for the NIRS light source outside the internal jugular vein. Meanwhile, a sample for blood gas analysis was obtained through the
\end{abstract}


central venous catheter. A correlation analysis between the $\mathrm{StO}_{2}$ and $\mathrm{ScvO}_{2}$ of 13 samples was performed (Pearson correlation coefficient), suggesting a high correlation between them $\left(\mathrm{r}=0.906, \mathrm{StO}_{2}=1.0018\right.$ $\mathrm{ScvO}_{2}+2.8524$ ). Bland-Altman analysis was also performed between the $\mathrm{StO}_{2}$ and $\mathrm{ScvO}_{2}$. Results were as follows: $100 \%$ of monitored points fell within the range of the mean $\pm 1.96 \mathrm{SD}$ of the difference between the $\mathrm{StO}_{2}$ and $\mathrm{ScvO}_{2}$; range of the mean $\pm 1.96 \mathrm{SD}$ of the difference between the $\mathrm{StO}_{2}$ and $\mathrm{ScvO}_{2}$ was $3 \pm 10.2$; confidence interval of the difference between the $\mathrm{StO}_{2}$ and $\mathrm{ScvO}_{2}$ was -7.2 to $13.2 \%$. The $\mathrm{StO}_{2}$ monitored with NIRS correlated highly with the $\mathrm{ScvO}_{2}$ measured in the internal jugular vein. Therefore, the $\mathrm{StO}_{2}$ can be used for directing clinical treatment with further research.

Key words: Central venous blood oxygen saturation; Internal jugular venous; Near infrared spectroscopy

\section{INTRODUCTION}

Severe septic shock is a common critical illness with a high mortality rate (Vincent et al., 2009; Shen et al., 2010). The Surviving Sepsis Campaign guidelines advocate early goaldirected therapy (EGDT), and central venous blood oxygen saturation $\left(\mathrm{ScvO}_{2}\right)$ monitoring is an important monitoring index of EGDT. In 2008, the International Guidelines for Management of Severe Sepsis and Septic Shock (Surviving Sepsis Campaign) proposed $\mathrm{ScvO}_{2}$ as one of the goals of fluid resuscitation (Dellinger et al., 2008), and it also exists in the 2012 version (Dellinger et al., 2013). The normal $\mathrm{ScvO}_{2}$ value ranges between 65 and $75 \%$; a value lower than $65 \%$ in critical disease is a warning signifying that the disease might progress to multiple organ dysfunction syndrome.

In patients with septic shock, $\mathrm{ScvO}_{2}$ must be monitored, but this requires central venous catheterization. If mixed venous oxygen saturation is monitored instead, balloon flotation catheter insertion is needed, and this is also an invasive procedure. Furthermore, in patients with septic shock who receive large doses of vasoactive drugs through central venous infusion, multiple collections of blood samples through the catheter may interfere with the continuous infusion of the drugs and affect the hemodynamics of the patients. Multiple blood sample collections can also lead to iatrogenic blood loss. The $\mathrm{ScvO}_{2}$ can be continuously monitored using an optical fiber probe inserted into the distal cavity of a plain central venous catheter through $\mathrm{CeVOX}^{\mathrm{TM}}$ system (Pulsion Medical Systems, Munich, Germany), but it is invasive and expensive, reducing its practical value. To perform noninvasive and continuous real-time monitoring of $\mathrm{ScvO}_{2}$ is of considerable importance for directing septic shock treatment.

Near infrared spectroscopy (NIRS) is an optical technology developed in recent years for the noninvasive detection of hemodynamic changes, with advantages of being real-time, continuous, low cost, and portable. NIRS has been widely used in the care of critically ill patients to detect blood oxygen saturation in the extremities. However, no one has previously reported on the use of NIRS to monitor the $\mathrm{ScvO}_{2}$ of critically ill patients.

We cooperated with the Medical Science and Technology Centre, School of Microelectronics and Solid-State Electronics, University of Electronic Science and Technology of China to monitor tissue blood oxygen saturation in the internal jugular venous area $\left(\mathrm{StO}_{2}\right)$ with 
NIRS using on a space-resolved (SR) algorithm. The aim of the present study was to determine whether a correlation exists between the $\mathrm{StO}_{2}$ data obtained with NIRS technology and $\mathrm{ScvO}_{2}$ and whether these two quantities are equivalent.

\section{MATERIAL AND METHODS}

\section{Settings and study population}

The present study was approved by the hospital Ethics Committee (Approval No. XHEC-D-2014-005), and informed consents were obtained from all patients or their family members. Inclusion criteria were as follows: age $>18$ years, surgery required because of illness (except for neck surgery), and internal jugular central venous catheterization performed before surgery. Family members or the patients themselves could ask to withdraw from the study at any time. To reduce interference from the carotid artery and adjacent tissue and to more precisely collect the data, we used ultrasound (MicroMaxx, SonoSite, USA) to locate the placement site for the NIRS light source outside the internal jugular vein (Figure 1).

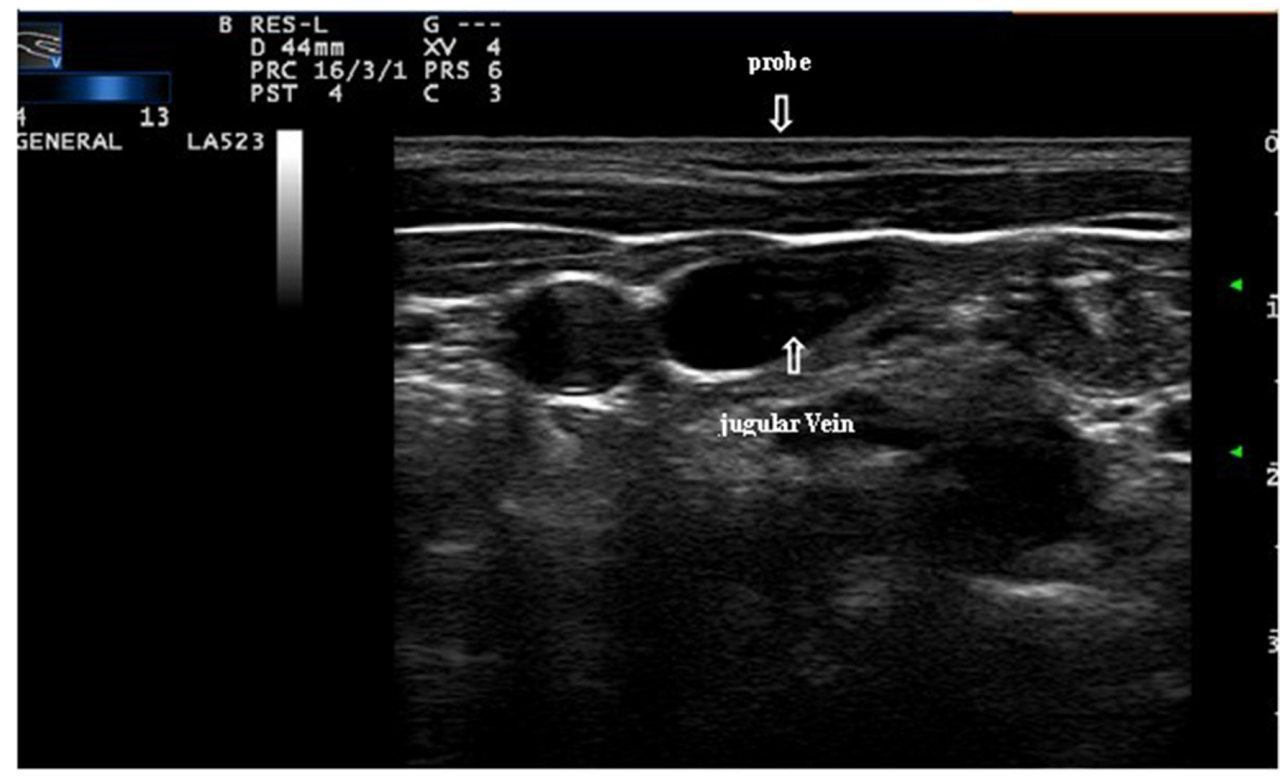

Figure 1. Ultrasound is used to localize the placement site for the near-infrared spectroscopy (NIRS) light source outside the internal jugular vein.

Signal collecting time was 5 minutes, and the collected signals belonged to the same person. Immediately after signal collecting was completed, a blood sample was obtained through the central venous catheter to be analyzed with a blood gas analytical instrument (ABL800, Radiometer, Denmark). Each patient served as his own control. On the day of surgery, data were monitored and collected, and a blood sample was taken from the central vein. Finally, the $\mathrm{ScvO}_{2}$ of the same patient at the same time through the central venous catheter was compared with the corresponding $\mathrm{StO}_{2}$, and the data were analyzed. 


\section{SR NIRS}

We used SR NIRS to monitor $\mathrm{StO}_{2}$. NIRS, which based on the optical property of human tissues combined with the transmission pattern through the tissue, detects and analyzes the concentration of physiological components reflected by the emergent light after the human tissue attenuation. Light within the near-infrared spectrum has good penetrating power in human tissue, and chromophores in the human body sensitive to near infrared light are important physiological components of oxygenated and deoxygenated hemoglobins, which have different spectrum properties (Jöbsis, 1977; Wilson et al., 1985). SR NIRS detects hemodynamic changes at dual wavelengths through 2 proximate channels that are designed to be located in almost the same tissue areas. Changes in the absolute concentrations of oxygenated hemoglobin and deoxygenated hemoglobin are differentially detected in order to detect local tissue blood oxygen saturation, based on the tiny spacing difference between the light-source detectors of these 2 channels. The reliability and detection precision of this technology have been fully verified in measurements of upper and lower limbs, breast, and brain (Ke et al., 2003; Fernandez et al., 2007; Hoshi, 2007).

The present research used the shock care SR NIRS instrument developed by the cooperation unit of the Medical Science and Technology Centre, School of Microelectronics and Solid-State Electronics, University of Electronic Science and Technology of China (Patents: Li, 2013; Li et al., 2013). The instrument consists of a probe, data acquisition and control module, calculation module, and power module. Connection of the instrument is shown in Figure 2.

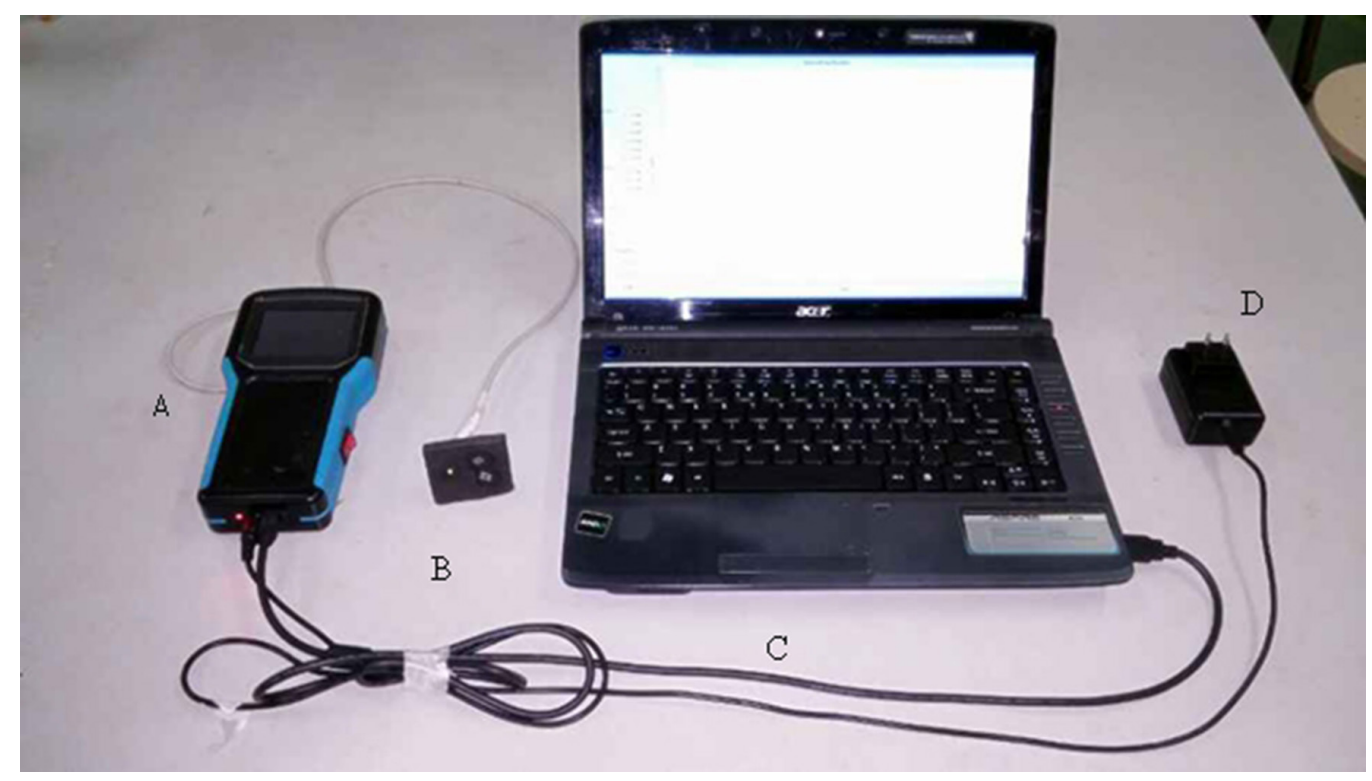

Figure 2. A. Probe; B. data acquisition and control module; C. calculation module; D. power module. 
The SR NIRS probe is designed to be placed on the skin overlying the internal jugular vein, as shown in Figure 1. The light source uses 3 wavelength-integrated light-emitting diodes of 735,805 , and $850 \mathrm{~nm}$, respectively. The light source of the probe and the 2 detectors form 2 detection channels, and the 2 detectors are close to each other, with their spacing to the light source being 2.3 and $2.5 \mathrm{~cm}$, respectively. The spacing was determined according to the optimization of light transmission simulation in a 3-dimensional model of jugular tissue ( $\mathrm{Li}$ et al., 2010). The probe is placed on the detection area, after being covered with disposable waterproof film, and is fixed with medical adhesive plaster. The calculation module converts the collected data of original light intensity changes into the data of local tissue blood oxygen saturation, using an algorithm based on the methods of Fantini (Fantini et al., 1999; Hueber et al., 1999) and Liu (Liu et al., 1995).

\section{Statistical analyses}

Distinct $\mathrm{ScvO}_{2}$ measurements were compared with $\mathrm{StO}_{2}$ values using the Bland-Altman method, and the correlation analysis was done using Pearson correlation coefficient. Data were analyzed using SPSS 17.0 (SPSS, Inc., Chicago, IL, USA). Statistical significance was accepted at $\mathrm{P}<0.05$.

\section{RESULTS}

All 13 study subjects were surgical patients with an average age of $79.92 \pm 7.49$ years, admitted to the Department of Anesthesia and Critical Care, Xin Hua Hospital Affiliated to Shanghai Jiao Tong University School of Medicine, between January 2014 and April 2014. No patient withdrew from the study during the research process. For detailed status of the patients, see Table 1.

\section{Table 1. Clinical characteristics of the study population.}

\begin{tabular}{lc}
\hline & $\mathrm{N}=13$ \\
\hline Age (years) & $79.9(7.49)$ \\
Gender & $8(61.5)$ \\
Male & $5(38.5)$ \\
Female & $1(7.7)$ \\
Diagnosis & $7(53.8)$ \\
Urolithiasis & $2(15.4)$ \\
Gastrointestinal perforation & $1(7.7)$ \\
Pneumonia & $1(7.7)$ \\
Right foot gangrene & $1(7.7)$ \\
Kidney cancer & $3(23.1)$ \\
Intestinal tumors & $75(10.2)$ \\
$\mathrm{Septic} \mathrm{shock}_{\mathrm{MAP}(\mathrm{mmHg})}$ & $7.39(0.09)$ \\
$\mathrm{PO}_{2}(\mathrm{kPa})$ & $15.94(2.90)$ \\
$\mathrm{PCO}_{2}(\mathrm{kPa})$ & $99.38(1.38)$ \\
$\left.\mathrm{SaO}_{2} \%\right)$ & $64.92(11.12)$ \\
$\mathrm{ScVO}_{2}(\%)$ & $67.90(12.29)$ \\
$\mathrm{StO}_{2}(\%)$ &
\end{tabular}

Age, MAP, $\mathrm{PO}_{2}, \mathrm{PCO}_{2}, \mathrm{SaO}_{2}, \mathrm{ScvO}_{2}$, and $\mathrm{StO}_{2}$ are reported as means (SD). Gender, diagnosis, and septic shock are reported as number (percentage). $\mathrm{MAP}=$ mean arterial pressure; $\mathrm{PO}_{2}=$ partial pressure of oxygen; $\mathrm{PCO}_{2}=$ partial pressure of carbon dioxide; $\mathrm{SaO}_{2}=$ oxygen saturation; $\mathrm{ScvO}_{2}=$ central venous blood oxygen saturation; $\mathrm{StO}_{2}=$ tissue oxygen saturation in the internal jugular venous area 
A correlation analysis between the $\mathrm{StO}_{2}$ and $\mathrm{ScvO}_{2}$ of 13 samples was performed (Pearson correlation coefficient), suggesting a high correlation between them $\left(\mathrm{r}=0.906, \mathrm{StO}_{2}\right.$ $\left.=1.0018, \mathrm{ScvO}_{2}+2.8524\right)$. Bland-Altman analysis was also performed between the $\mathrm{StO}_{2}$ and $\mathrm{ScvO}_{2}$, and the results were as follows: $100 \%$ of monitored points fell within the range of the mean $\pm 1.96 \mathrm{SD}$ of the difference between the $\mathrm{StO}_{2}$ and $\mathrm{ScvO}_{2}$, range of the mean $\pm 1.96 \mathrm{SD}$ of the difference between the $\mathrm{StO}_{2}$ and $\mathrm{ScvO}_{2}$ was $3 \pm 10.2$, and the confidence interval of the difference between the $\mathrm{StO}_{2}$ and $\mathrm{ScvO}_{2}$ was -7.2 to 13.2\%. The results are shown in Figures 3 and 4 .

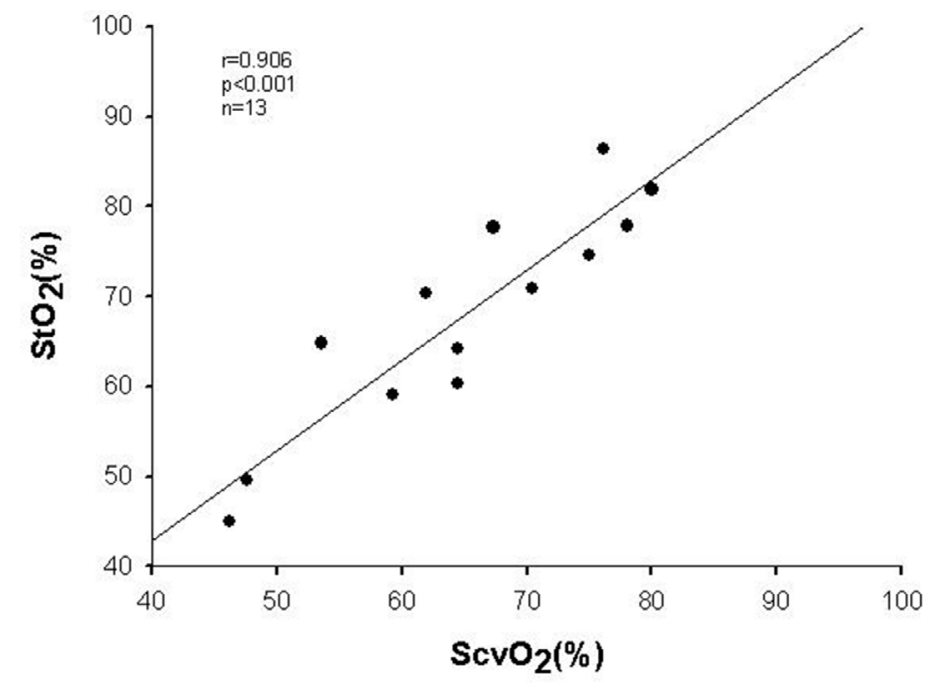

Figure 3. Linear regression plot of the correlation between the tissue blood oxygen saturation in the internal jugular venous area $\left(\mathrm{StO}_{2}\right)$ and the central venous blood oxygen saturation $\left(\mathrm{ScvO}_{2}\right)$ of 13 samples (Pearson correlation coefficient).

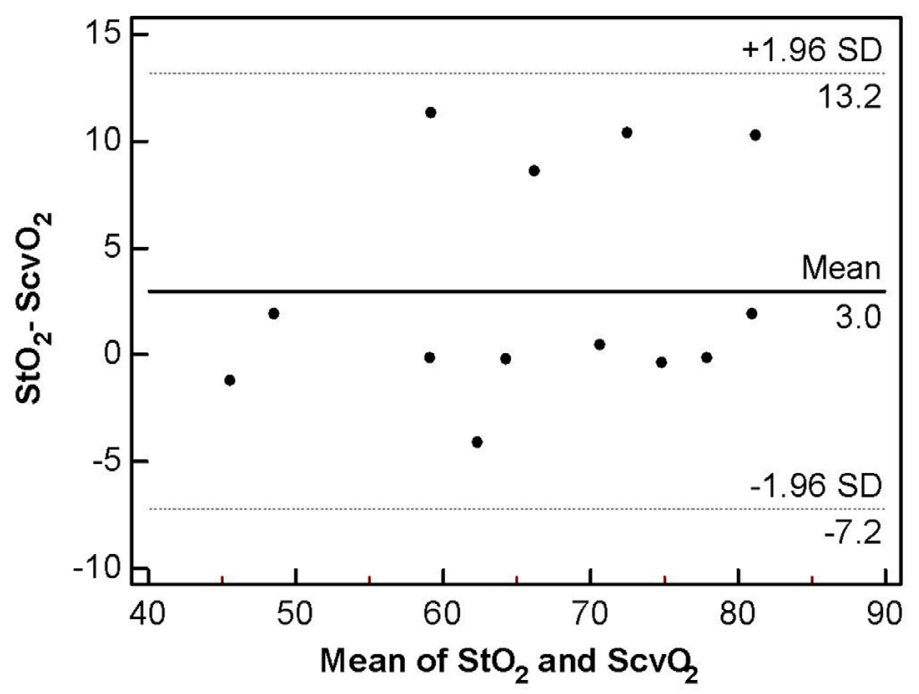

Figure 4. Bland-Altman plot of differences plotted against means of the tissue blood oxygen saturation in the internal jugular venous area $\left(\mathrm{StO}_{2}\right)$ and the central venous blood oxygen saturation $\left(\mathrm{ScvO}_{2}\right)$ for all data points. 


\section{DISCUSSION}

Fluid resuscitation treatment of patients with septic shock is currently a research focus in the field of critical care medicine. Many studies have shown that in the early stages of resuscitation of patients with septic shock, a decrease in $\mathrm{ScvO}_{2}$ is an important manifestation of inadequate tissue perfusion (Marx and Reinhart, 2006). In a retrospective study on the performance of the international guidelines for septic shock treatment (Levy et al., 2010), Levy reported that the hospital mortality in patients with septic shock had decreased from 37 to $30.8 \%$ after 3 years of implementation of the guidelines. This study included 15,022 patients in 165 medical centers in Europe and the USA between January 2005 and March 2008. In 2011, Chamberlain performed a meta-analysis of 253 studies from 2004 onward, comprising 23,438 patients, and found that during bundle therapy of patients with sepsis, the strategy to use the $\mathrm{ScvO}_{2}$ parameter as an early goal could significantly affect the patient's prognosis (Chamberlain et al., 2011). Therefore, monitoring of $\mathrm{ScvO}_{2}$ plays a considerably important role in the fluid resuscitation of septic shock, and a real-time, noninvasive instrument to monitor $\mathrm{ScvO}_{2}$ is needed. Unfortunately, few relevant studies have been done on the noninvasive, continuous monitoring of the $\mathrm{ScvO}_{2}$ of adult patients. Obviously, our study is a creative exploration in this area. Septic shock patients need large amounts of fluid resuscitation, but excessive fluid may cause serious complications, such as pulmonary edema. A single $\mathrm{ScvO}_{2}$ measurement obviously cannot fully meet the needs of patients with severe septic shock, whereas noninvasive, continuous monitoring of the $\mathrm{ScvO}_{2}$ can provide better information and avoid excessive fluid replacement.

In our study, the $\mathrm{StO}_{2}$ obtained using NIRS technology correlated highly with the $\mathrm{ScvO}_{2}(\mathrm{r}=0.906)$. This finding suggests the possibility of noninvasive, continuous monitoring of the $\mathrm{ScvO}_{2}$. If this could be applied clinically, it could better direct the fluid resuscitation of patients with septic shock. This would be especially useful for patients for whom invasive procedures are not suitable or who wish to avoid them. A correlation between the $\mathrm{StO}_{2}$ and $\mathrm{ScvO}_{2}$ has been show in similar studies such as that of Tortoriello et al., (2005), which used the NIRS system to evaluate the $\mathrm{StO}_{2}$ in pediatric cardiac surgery. Another study used the NIRS system combined with transesophageal echocardiography to monitor the oxygen saturation of the left and right ventricles (Margreiter et al., 2002) and showed that NIRS was fully feasible for the evaluation of the oxygen saturation of internal organs and large blood vessels. The system we used had previously been successfully used for evaluation of the working memory of the brain ( $\mathrm{Li}$ et al., 2009). In the present study, we modified the system to monitor the $\mathrm{StO}_{2}$.

In our study, 3 patients with shock received large doses of vasoactive drugs, and the NIRS-monitored data were basically consistent with the $\mathrm{ScvO}_{2}$ values measured by blood gas analysis. The internal jugular vein is the major vein of the body, and even during shock, it is far less affected than other smaller veins, so the data it provides is relatively stable.

The left common carotid artery comes from the aortic arch, while the right common carotid artery is a branch of the brachiocephalic trunk, and the internal jugular vein is lateral to the carotid artery. Previous studies reported motion artifact interference signals in measurements due to the pulsation of large arteries, leading to a shift in the pulse oxygen saturation (Sahni et al., 2003; Petterson et al., 2007). However, in previous data acquisition, we obtained stable values under the reduced influence of motion artifacts, and in the program design of the present study, we fully considered relevant factors and attenuated the influence of motion in the data analysis. Furthermore, the soft tissue between the internal jugular vein and carotid artery reduces the arterial pulse noise to a certain extent. During the process of data collec- 
tion, we used ultrasound localization to avoid interference from the carotid artery as much as possible, which significantly improved the accuracy of the NIRS monitoring. Nevertheless, in 2 cases, the signal data we collected gave higher $\mathrm{StO}_{2}$ values than the $\mathrm{ScvO}_{2}$ values in the blood samples, indicating some interference from signals of the carotid artery. How to more effectively remove such signal noise (e.g., from the carotid artery and its adjacent tissue) to calibrate the parameters using the blood gas analytical instrument at an early stage is part of the next step in our work.

The $\mathrm{StO}_{2}$ monitored with NIRS technology correlated highly with the $\mathrm{ScvO}_{2}$ measured through an internal jugular central venous catheter. Accordingly, it can be used for directing clinical treatment, with further research to improve its precision. Its correlation with $\mathrm{SvO}_{2}$ can also be further studied using a balloon flotation catheter. Another application for the NIRS technology could be to simultaneously monitor the oxygen levels in the internal jugular and femoral veins. Previous studies have shown that the $\mathrm{ScvO}_{2}$ of the superior vena cava and that of the inferior vena cava are not the same, and it is not worth performing invasive procedures in two sites merely for monitoring $\mathrm{ScvO}_{2}$.

\section{ACKNOWLEDGMENTS}

Research supported by grants from the National Natural Science Foundation of China (NSFC) (\# 81272144, \#81372100), the Shanghai Municipal Health and Family Planning Commission (\#20114217) and the Fund of Xin Hua Hospital (\#13YJ12).

\section{REFERENCES}

Chamberlain DJ, Willis EM and Bersten AB (2011). The severe sepsis bundles as processes of care: a meta-analysis. Aust. Crit. Care 24: 229-243.

Dellinger RP, Levy MM, Carlet JM, Bion J, et al. (2008). Surviving Sepsis Campaign: international guidelines for management of severe sepsis and septic shock: 2008. Crit. Care Med. 36: 296-327.

Dellinger RP, Levy MM, Rhodes A, Annane D, et al. (2013). Surviving Sepsis Campaign: international guidelines for management of severe sepsis and septic shock, 2012. Intensive Care Med. 39: 165-228.

Fantini S, Hueber D, Franceschini MA, Gratton E, et al. (1999). Non-invasive optical monitoring of the newborn piglet brain using continuous-wave and frequency-domain spectroscopy. Phys. Med Biol. 44: 1543-1563.

Fernandez M, Burns K, Calhoun B, George S, et al. (2007). Evaluation of a new pulse oximeter sensor. Am. J. Crit. Care 16: $146-152$.

Hoshi Y (2007). Functional near-infrared spectroscopy: current status and future prospects. J. Biomed. Opt. 12: 062106.

Hueber DM, Fantini S, Cerussi AE and Barbieri B (1999). New optical probe designs for absolute (self-calibrating) NIR tissue hemoglobin measurements. SPIE 3597: 618-631.

Jöbsis FF (1977). Noninvasive, infrared monitoring of cerebral and myocardial oxygen sufficiency and circulatory parameters. Science. 198: 1264-1267.

Ke S, Wen X, Gurfinkel M, Charnsangavej C, et al. (2003). Near-infrared optical imaging of epidermal growth factor receptor in breast cancer xenografts. Cancer Res. 63: 7870-7875.

Levy MM, Dellinger RP, Townsend SR, Linde-Zwirble WT, et al. (2010). The Surviving Sepsis Campaign: results of an international guideline-based performance improvement program targeting severe sepsis. Intensive Care Med. 36: 222-231.

Li T (2013). A detection device of the absolute amount of human blood oxygen saturation and the method thereof. Invention patent No. 20130644371.9.

Li T, Li L, Luo Q and Gong H (2009). Assessing working memory in real-life situations with functional near-infrared spectroscopy. J. Innov. Opt. Health Sci. 2: 423-430.

Li T, Gong H and Luo Q (2010). MCVM: Monte Carlo modeling of photon migration in voxelized media. J. Innov. Opt. Health Sci. 3: 91-102. 
Li T, Zhao Y, Sun YL, et al. (2013). A detection device and its detection method of the absolute amount of local brain tissue blood oxygen saturation. Invention patent No. 201310726021.7.

Liu H, Boas DA, Zhang Y, Yodh AG, et al. (1995). Determination of optical properties and blood oxygenation in tissue using continuous NIR light. Phys. Med. Biol. 40: 1983-1993.

Margreiter J, Keller C and Brimacombe J (2002). The feasibility of transesophageal echocardiograph-guided right and left ventricular oximetry in hemodynamically stable patients undergoing coronary artery bypass grafting. Anesth. Analg. 94: 794-798.

Marx G and Reinhart K (2006). Venous oximetry. Curr. Opin. Crit. Care 12: 263-268.

Petterson MT, Begnoche VL and Graybeal JM (2007). The effect of motion on pulse oximetry and its clinical significance. Anesth. Analg. 105 (6 Suppl): S78-S84.

Sahni R, Gupta A, Ohira-Kist K and Rosen TS (2003). Motion resistant pulse oximetry in neonates. Arch. Dis. Child Fetal Neonatal Ed. 88: F505-F508.

Shen HN, Lu CL and Yang HH (2010). Epidemiologic trend of severe sepsis in Taiwan from 1997 through 2006. Chest 138: 298-304.

Tortoriello TA, Stayer SA, Mott AR, McKenzie ED, et al. (2005). A noninvasive estimation of mixed venous oxygen saturation using near-infrared spectroscopy by cerebral oximetry in pediatric cardiac surgery patients. Paediatr. Anaesth. 15: 495-503.

Vincent JL, Rello J, Marshall J, Silva E, et al. (2009). International study of the prevalence and outcomes of infection in intensive care units. JAMA 302: 2323-2329.

Wilson BC, Jeeves WP and Lowe DM (1985). In vivo and post mortem measurements of the attenuation spectra of light in mammalian tissues. Photochem. Photobiol. 42: 153-162. 